\title{
Pemodelan Semiparametrik Geographical Weighted Logistic Regression pada Data Kemiskinan di Provinsi Sulawesi Selatan Tahun 2017
}

\author{
Fitriatusakiah $^{1^{*}}$, Andi Kresna Jaya ${ }^{2}$, La Podje Talangko ${ }^{3}$ \\ ${ }^{123}$ Departemen Statistika, Fakultas MIPA \\ Universitas Hasanuddin, Makassar, 90245, Indonesia \\ * Corresponding author, email: zakiah290@gmail.com
}

\begin{abstract}
The level of poverty in a Regency/city in South Sulawesi in 2017 is different. The grouping of poverty status can be done based on the value of Head Count Index (HCI) of South Sulawesi. Factors affecting poverty will differ for each area being observed. Statistical modeling method developed for data analysis by taking into account the location factor is semiparametric Geographical Weighted Logistic Regression (GWLR). The GWLR semiparametric Model consists of parameters that are affected by the location and not affected by the location. The parameter estimator of the GWLR semiparametric model used in this research was obtained using the maximum method likelihood estimation. The result of a semiparametric model of GWLR each district/city in South Sulawesi in 2017 has the value Estimator parameter for global parameters is the same value for each location, namely $\alpha_{3}=0.1724, \alpha_{4}=0.0204$ and $\alpha_{6}=0.0261$ whereas the parameter estimator for local parameters has different values so that GWLR semiparametric model of each districh/tcity.
\end{abstract}

Keywords: Proverty, HCI, GWLR Semiparametric, Maximum Likelihood Estimation

\begin{abstract}
Abstrak
Tingkat kemiskinan di suatu kabupaten/kota di Provinsi Sulawesi Selatan tahun 2017 berbeda-beda. Pengelompokan status kemiskinan dapat dilakukan berdasarkan nilai Head Count Index (HCI) Provinsi Sulawesi Selatan. Faktor yang mempengaruhi kemiskinan akan berbeda untuk setiap daerah yang diamati. Metode pemodelan statistika yang dikembangkan untuk analisis data dengan memperhitungkan faktor lokasi yaitu semiparametrik Geographical Weighted Logistic Regression (GWLR). Model semiparametrik GWLR terdiri dari parameter yang dipengaruhi lokasi dan tidak dipengaruhi lokasi. Penaksir parameter model semiparametrik GWLR yang digunakan pada penelitian ini diperoleh menggunakan metode maximum likelihood estimation. Hasil yang diperoleh yaitu model semiparametrik GWLR tiap kabupaten/kota di Sulawesi Selatan tahun 2017 memiliki nilai penaksir parameter untuk parameter global adalah bernilai sama untuk setiap lokasi yaitu $\alpha_{3}=0.1724, \alpha_{4}=0.0204$ dan $\alpha_{6}=0.0261$ sedangkan hasil penaksir parameter untuk parameter lokal memiliki nilai yang berbeda-beda sehingga model semiparametrik GWLR tiap kabupaten/kota berbeda-beda.
\end{abstract}

Kata Kunci: Kemiskinan, HCI, Semiparametrik GWLR, Maximum Likelihood Estimation

Estimasi: Journal of Statistics and Its Application

e-ISSN: 2721-3803, p-ISSN: 2721-379X

http://journal.unhas.ac.id/index.php/ESTIMASI 


\section{Pendahuluan}

Provinsi Sulawesi Selatan merupakan salah satu daerah di Indonesia yang masih menghadapi permasalahan kemiskinan. Berdasarkan data resmi yang dirilis oleh BPS hingga tahun 2017, penduduk dengan keadaan miskin di Provinsi Sulawesi Selatan mencapai 9.38 persen dari total penduduk yang bermukim di Provinsi Sulawesi Selatan. Karakteristik kemiskinan Sulawesi Selatan dapat dilihat dari kondisi demografi, pendidikan dan ketenagakerjaan dari kepala rumah tangga; kondisi perumahan; dan persebarannya menurut pulau. Pemahaman mengenai karakteristik kemiskinan penting sebagai dasar dalam penyusunan kebijakan dan program pengentasan kemiskinan agar tepat sasaran Untuk mengukur kemiskinan, Badan Pusat Statistik (BPS) menggunakan konsep kemampuan memenuhi kebutuhan dasar (basic needs approach). Dengan pendekatan ini, dapat dihitung Head Count Index (HCI), yaitu persentase penduduk miskin terhadap total penduduk. [1].

Tingkat kemiskinan suatu daerah dan factor-faktor yang mempengaruhinya, mungkin akan berbeda untuk setiap daerah tergantung pada kondisi daerah yang diamati. Oleh karena itu diperlukan suatu pemodelan statistik yang memperhatikan lokasi. Metode statistik yang telah dikembangkan untuk analisis data dengan memperhitungkan faktor lokasi yaitu semiparametrik Geographical Weighted Logistic Regression (GWLR). Model semiparametrik GWLR terdiri dari parameter yang dipengaruhi lokasi (geographically varying coefficient) dan parameter yang tidak dipengaruhi lokasi (fixed coefficiet) [2]. Penaksir parameter model semiparametrik GWLR yang digunakan pada penelitian ini diperoleh menggunakan metode maximum likelihood estimation dengan memberikan pembobot yang berbeda pada setiap lokasi.

Oleh karena itu, dalam penelitian ini dibahas mengenai pemodelan semiparametrik geographical weighted logistic regression pada data kemiskinan di Provinsi Sulawesi Selatan tahun 2017 menggunakan model linier koregionalisasi untuk memperoleh parameter yang dipengaruhi lokasi (parameter lokal) dan parameter yang tidak dipengaruhi lokasi (parameter global) dengan pembobot fixed Gaussian kernel.

\section{Material dan Metode}

\subsection{Sumber Data}

Penelitian ini menggunakan data sekunder tentang tingkat kemiskinan di Sulawesi Selatan tahun 2017 yang diperoleh dari www.bps.go.id. Data ini terdiri dari 24 kabupaten/kota. Variabel respon bersifat kategori yaitu dengan mengelompokkan kabupaten/kota menjadi miskin atau tidak miskin berdasarkan pada nilai Head Count Index (HCI) Provinsi Sulawesi Selatan. Variabel prediktor terdiri dari persentase rumah dengan dinding tembok dan kayu, persentase rumah dengan atap beton, genteng seng dan asbes, persentase rumah dengan lantai bukan tanah, persentase rumah dengan luas lantai $<8 \mathrm{~m}^{2}$ per orang, persentase rumah dengan status kepemilikan sendiri, tingkat partisipasi angkatan kerja dan persentase rumah dengan status kepemilikan kontrak/sewa. 


\subsection{Semiparametrik Geographical Weighted Logistic Regression}

Pada model semiparametrik GWLR, variabel respon $(y)$ diprediksi berdasarkan variabel prediktor $(x)$ yang masing-masing koefisien regresinya $\beta_{j}\left(u_{i}, v_{i}\right)$ bergantung pada lokasi data tersebut diamati dan koefisien regresi $\alpha_{m}$ tidak bergantung pada lokasi (konstan). Model semiparametrik GWLR dapat dituliskan seperti berikut.

$$
\pi\left(x_{i}\right)=\frac{\exp \left(\beta_{0}\left(u_{i}, v_{i}\right)+\sum_{j=1}^{k^{*}} \beta_{j}\left(u_{i}, v_{i}\right) x_{i j}+\sum_{m=k^{*}+1}^{k} \alpha_{m} x_{i m}\right)}{1+\exp \left(\beta_{0}\left(u_{i}, v_{i}\right)+\sum_{j=1}^{k^{*}} \beta_{j}\left(u_{i}, v_{i}\right) x_{i j}+\sum_{m=k^{*}+1}^{k} \alpha_{m} x_{i m}\right)},
$$

dengan $i=1,2, \ldots, n ; j=1,2, \ldots, k$. Prosedur penaksiran parameter pada model semiparametrik GWLR menggabungkan mekanisme parametrik untuk menaksir parameter global atau parameter yang bernilai konstan dan non parametrik untuk menaksir parameter lokal atau parameter yang dipengaruhi lokasi [2]. Pada model semiparametrik GWLR, metode penaksir parameter yang digunakan adalah metode MLE. Selanjutnya karena hasil turunan pertama fungsi log likelihood terhadap masingmasing parameter tidak dapat diselesaikan secara analitik, maka digunakan metode iterasi Newton Raphson sebagai berikut:

$$
\begin{aligned}
\left(\boldsymbol{\beta}^{(t+1)}\left(u_{i}, v_{i}\right), \boldsymbol{\alpha}^{(t+1)}\right)= & \boldsymbol{\beta}^{(t)}\left(u_{i}, v_{i}\right), \boldsymbol{\alpha}^{(t)} \\
& \left.-\left(\boldsymbol{H}^{(t)^{-1}}\left(\boldsymbol{\beta}^{(t)}\left(u_{i}, v_{i}\right), \boldsymbol{\alpha}^{(t)}\right)\right) \boldsymbol{g}^{(t)}\left(\boldsymbol{\beta}^{(t)}\left(u_{i}, v_{i}\right), \boldsymbol{\alpha}^{(t)}\right)\right),
\end{aligned}
$$

\subsection{Analisis Variogram}

Variogram merupakan statistik deskriptif yang dapat memperlihatkan secara grafik kontinuitas spasial, karena jika ada dua buah nilai spasial yang letaknya berdekatan, maka akan relatif bernilai sama dibandingkan dengan dua buah nilai spasial yang letaknya berjauhan [3]. Variogram dapat menggambarkan hubungan spasial antar variabel dan dinyatakan sebagai $2 \gamma(h)$. Variogram dirumuskan sebagai berikut :

$$
2 \gamma(h)=E\left[\left(x_{i}-x_{i^{*}}\right)^{2}\right],
$$

dengan $\gamma(h)$ disebut sebagai semivariogram.

Beberapa parameter yang digunakan untuk mencari nilai dalam model semivariogram yaitu:

1. Pengaruh nugget menyatakan keragaman yang dikarenakan satu atau beberapa faktor, seperti sifat keragaman spasial variabel, faktor eksternal yang tidak diukur, kesalahan pengukuran dan ketiadaan informasi karena jarak yang sangat kecil. Selain itu, ukuran pengaruh non-nugget (skala spasial kecil dan skala spasial besar) menyatakan persentase pengaruh spasial yang dapat dimodelkan [4].

2. Sill (c) adalah nilai struktur korelasi spasial tertinggi saat dimana nilai semivariogram pada jarak tertentu cenderung mencapai nilai yang stabil [5].

3. Range (a) merupakan jarak pada saat semivariogram mencapai nilai sill

Nilai yang diperoleh dari model semivariogram akan digunakan untuk membandingkan nilai MSE. 
Terdapat beberapa jenis model semivariogram dasar yang sering digunakan, yaitu [3]:

1. Model Nugget

2. Model Spherical

$$
g(h)= \begin{cases}0, & \text { untuk } h=0 \\ 1, & \text { untuk } h>0\end{cases}
$$

$$
g(h)=\left\{\begin{array}{cr}
{\left[\left(\frac{3 h}{2 a}\right)-0,5\left(\frac{h}{a}\right)^{3}\right],} & \text { untuk } 0 \leq h<a, \\
1, & \text { untuk } h \geq a .
\end{array}\right.
$$

3. Model Eksponensial

$$
g(h)=\left[1-\exp \left(-\frac{3 h}{a}\right)\right]
$$

4. Model Gaussian

$$
g(h)=\left[1-\exp \frac{-3 h^{2}}{a^{2}}\right]
$$

dengan $h$ adalah jarak antara dua titik sampel.

\subsection{Model Linier Koregionalisasi}

Model Linier Koregionalisasi (MLK) merupakan metode yang berguna untuk menggambarkan hubungan spasial antar variabel [6]. Isaaks \& Srivastava (1989) menyatakan MLK terdiri dari semivariogram dan semivariogram silang dari dua atau lebih variabel. MLK terbentuk dari model struktur tersarang dari kombinasi linier model semivariogram dasar sebagai berikut:

$$
\gamma_{i j}(h)=\sum_{s=0}^{m} c_{i j, s} g_{s}\left(h_{s}\right),
$$

dengan $i=1,2, \ldots, p, j=1,2, \ldots, p, p$ merupakan banyaknya variabel, $s$ merupakan struktur model dengan $s=0,1,2, \ldots, m$ dan $m$ merupakan jumlah struktur tersarang model yang digunakan. MLK yang digunakan terbentuk dari model struktur tersarang yang terdiri dari pengaruh nugget dan dua model semivariogram dasar. Matriks koregionalisasi $\boldsymbol{c}_{s}$ adalah matriks korelasi yang dapat dipandang sebagai partisi matriks ragam-peragam yang menggambarkan struktur korelasi pada jarak spasial yang berbeda.

\subsection{Multikolinieritas}

Pada analisis regresi logistik tidak diperkenankan terjadi kasus multikolinieritas. Metode untuk menguji adanya multikolinieritas dapat dilihat pada tolerance value atau Variance Inflation Factor (VIF). Nilai VIF dapat diperoleh dengan rumus berikut :

$$
V I F=\frac{1}{\text { tolerance }}=\left(1-R_{j}^{2}\right)^{-1},
$$

dengan $R_{j}{ }^{2}$ adalah koefisien detrminasi antara $x$ dengan variabel prediktor lain. 


\subsection{Heterogenitas Spasial}

Heterogenitas spasial terjadi akibat adanya perbedaan antara satu wilayah dengan wilayah lainnya. Adanya penyimpangan asumsi ini (heteroskedastisitas) dalam regresi dapat diketahui dengan menggunakan beberapa cara, salah satunya adalah uji BreuschPagan [7].

Hipotesis:

$\mathrm{H}_{0}:{\sigma_{1}}^{2}={\sigma_{2}}^{2}=\cdots={\sigma_{n}}^{2}=\sigma^{2}$ (terjadi homoskedastisitas)

$\mathrm{H}_{1}$ : Minimal ada satu $\sigma_{1}{ }^{2} \neq \sigma^{2}$ (terjadi heteroskedastisitas)

Statistik uji:

$$
B P=\left(\frac{1}{2}\right) \boldsymbol{f}^{\boldsymbol{T}} \boldsymbol{Z}\left(\boldsymbol{Z}^{\boldsymbol{T}} \boldsymbol{Z}\right)^{-\mathbf{1}} \boldsymbol{Z}^{\boldsymbol{T}} \boldsymbol{f} \sim \chi^{2}{ }_{(k-1)}{ }^{\prime}
$$

dengan elemen vector $f$ adalah $f_{i}=\left(\frac{e_{i}^{2}}{\sigma^{2}}\right)-1$ dimana $e_{i}=y_{i}-\bar{y}$ adalah residual untuk pengamatan ke-i, $\sigma^{2}$ adalah ragam residual dan Z merupakan matriks berukuran $n \times(k+$ 1 berisi vektor yang sudah di normalstandarkan untuk tiap pengamatan.

\subsection{Penentuan bandwidth}

Fungsi dari bandwidth adalah untuk menentukan bobot dari suatu lokasi terhadap lokasi lain yang digunakan sebagai pusat. Ada beberapa metode yang digunakan untuk memilih bandwidth optimum, salah satunya adalah validasi silang atau cross validation (CV) dengan rumus:

$$
C V(h)=\sum_{i=1}^{n}\left(y_{i}-\hat{y}_{\neq i}(h)\right)^{2}
$$

Dengan $\hat{y}_{\neq i}(h)$ yaitu nilai penaksir $y_{i}$ (fitting value) dengan pengamatan di lokasi $\left(u_{i}, v_{i}\right.$ ) dihilangkan dalam proses penaksiran, $y_{i}$ adalah pengamatan ke- $I$ dan $n$ adalah jumlah sampel [8]. Untuk mendapatkan nilai $h$ yang optimal, maka diperoleh dari $h$ yang menghasilkan nilai CV yang minimum (Fortheringham et al. 2002). Sebelum pembobot ditentukan, harus dihitung dahulu $d_{i j}$ yang merupakan jarak lokasi $\left(u_{i}, v_{i}\right)$ menggunakan jarak euclidian yaitu [9]:

$$
d_{i j}=\sqrt{\left(u_{i}-u_{j}\right)^{2}+\left(v_{i}-v_{j}\right)^{2}}
$$

Pada penelitian ini, fungsi pembobot spasial yang digunakan adalah fixed Gaussian kernel. Fungsi fixed Gaussian kernel:

$$
w_{i j}\left(u_{i}, v_{i}\right)=\exp \left[-\frac{1}{2}\left(\frac{d_{i j}}{h}\right)^{2}\right]
$$




\section{Hasil dan Diskusi}

\subsection{Uji Multikolinieritas}

Adapun cara mendeteksi adanya multikolinieritas adalah dengan melihat nilai VIF. Jika nilai VIF lebih kecil daripada 10 maka dapat disimpulkan tidak terjadi multikolinearitas.

Tabel 1. Hasil pengujian asumsi multikolinieritas

\begin{tabular}{ccc}
\hline Variabel Prediktor & VIF & Keterangan \\
\hline$x_{1}$ & 1.9145 & Tidak terjadi multikolinieritas \\
\hline$x_{2}$ & 5.9623 & Tidak terjadi multikolinieritas \\
\hline$x_{3}$ & 7.2347 & Tidak terjadi multikolinieritas \\
\hline$x_{4}$ & 3.3610 & Tidak terjadi multikolinieritas \\
\hline$x_{5}$ & 7.2482 & Tidak terjadi multikolinieritas \\
\hline$x_{6}$ & 2.1835 & Tidak terjadi multikolinieritas \\
\hline$x_{7}$ & 5.5206 & Tidak terjadi multikolinieritas \\
\hline
\end{tabular}

Pada Tabel 1 dapat disimpulkan bahwa data yang digunakan tidak mengandung multikolinieritas dikarenakan nilai VIF pada setiap variabel kurang dari 10. Oleh karena itu, semua variabel prediktor dalam data tersebut dapat digunakan dalam penelitian.

\subsection{Uji Heterogenitas Spasial}

Pengujian heterogenitas spasial menggunakan uji BP. Hipotesis yang digunakan adalah sebagai berikut:

$\mathrm{H}_{0}:{\sigma_{1}}^{2}={\sigma_{2}}^{2}=\cdots={\sigma_{n}}^{2}=\sigma^{2}$

$\mathrm{H}_{1}$ : Minimal ada satu $\sigma_{1}{ }^{2} \neq \sigma^{2}$

Statistik uji:

$B P=\left(\frac{1}{2}\right) \boldsymbol{f}^{T} \boldsymbol{Z}\left(\boldsymbol{Z}^{T} \boldsymbol{Z}\right)^{-\mathbf{1}} \boldsymbol{Z}^{T} \boldsymbol{f}$

$=22.32$

Berdasarkan dari hasil analisis yang telah dilakukan, diperoleh nilai $\mathrm{BP}=22.32>$ $\chi_{(6 ; 0,05)}^{2} 12.592$ maka $H_{0}$ ditolak, diperoleh keputusan bahwa terjadi heterogenitas spasial. Sehingga dapat disimpulkan bahwa pemodelan regresi yang tepat untuk digunakan adalah dengan memperhatikan lokasi.

\subsection{Menentukan Variabel Lokal dan Variabel Global}

MLK terdiri dari semivariogram dan semivariogram silang yang masing-masing terbentuk dari struktur tersarang model-model semivariogram dasar. Untuk menentukan 
dua model semivariogram dasar yang digunakan maka dilakukan perbandingan terhadap nilai MSE masing-masing model, model $\mathrm{Nug}(0)+\operatorname{Exp}(22.57)+\operatorname{Sph}(28.49)$ memiliki nilai MSE paling kecil yaitu sebesar 0.61512484. Model terbaik yang diperoleh digunakan untuk menduga matriks koregionalisasi. Berdasarkan matriks koregionalisasi tersebut, diperoleh persentase keragaman spasial setiap variabel yang ditunjukkan pada Tabel 2.

Tabel 1. Persentase pengaruh spasial

\begin{tabular}{cc}
\hline Variabel & Pengaruh Spasial Variabel (\%) \\
\hline$x_{1}$ & 79.0259 \\
\hline$x_{2}$ & 91.9570 \\
\hline$x_{3}$ & 73.2790 \\
\hline$x_{4}$ & 74.3945 \\
\hline$x_{5}$ & 83.8024 \\
\hline$x_{6}$ & 46.5175 \\
\hline$x_{7}$ & 82.3454 \\
\hline
\end{tabular}

Pada Tabel 2, terlihat bahwa variabel yang memiliki persentase pengaruh spasial tinggi adalah variabel $x_{1}$ sebesar $79.0259 \%, x_{2}$ yaitu sebesar $91.9570 \%, x_{5}$ sebesar 83.8024 dan $x_{7}$ sebesar $82.3454 \%$. Variabel tersebut ditetapkan sebagai variabel lokal pada model semiparametrik GWLR.

\subsection{Penaksir Parameter Model Semiparametrik Geographical Weighted Logistic Regression}

Pada model semiparametrik GWLR, metode penaksir parameter yang digunakan adalah metode Maksimum Likelihood Estimation (MLE). Persamaan fungsi log likelihood adalah sebagai berikut:

$$
\begin{aligned}
\ln L\left(\beta\left(u_{i}, v_{i}\right), \alpha_{m}\right) & =\sum_{i=1}^{n} y_{i}\left(\beta_{0}\left(u_{i}, v_{i}\right)+\sum_{j=1}^{k^{*}} \beta_{j}\left(u_{i}, v_{i}\right) x_{i j}+\sum_{m=k^{*}+1}^{k} \alpha_{m} x_{i m}\right) \\
& -\sum_{i=1}^{n} \ln \left\{1+\exp \left(\beta_{0}\left(u_{i}, v_{i}\right)+\sum_{j=1}^{k^{*}} \beta_{j}\left(u_{i}, v_{i}\right) x_{i j}+\sum_{m=k^{*}+1}^{k} \alpha_{m} x_{i m}\right)\right\}
\end{aligned}
$$

Faktor letak geografis merupakan faktor pembobot pada model semiparametrik GWLR. Pembobot dimasukkan pada persamaan fungsi log likelihood yaitu:

$\ln L^{*}\left(\beta\left(u_{i}, v_{i}\right), \alpha_{m}\right)$

$$
=\sum_{i=1}^{n} w_{i j}\left(u_{i}, v_{i}\right) y_{i}\left(\beta_{0}\left(u_{i}, v_{i}\right)+\sum_{j=1}^{k^{*}} \beta_{j}\left(u_{i}, v_{i}\right) x_{i j}+\sum_{m=k^{*}+1}^{k} \alpha_{m} x_{i m}\right)
$$




$$
-\sum_{i=1}^{n} w_{i j}\left(u_{i}, v_{i}\right) \ln \left\{1+\exp \left(\beta_{0}\left(u_{i}, v_{i}\right)+\sum_{j=1}^{k^{*}} \beta_{j}\left(u_{i}, v_{i}\right) x_{i j}+\sum_{m=k^{*}+1}^{k} \alpha_{m} x_{i m}\right)\right\}
$$

Untuk mendapatkan estimasi parameter terhadap $\beta\left(u_{i}, v_{i}\right)$ dan $\alpha_{m}$, maka persamaan $\ln L^{*}\left(\beta\left(u_{i}, v_{i}\right), \alpha_{m}\right)$ diturunkan terhadap $\beta\left(u_{i}, v_{i}\right)$ dan $\alpha_{m}$ kemudian disamakan dengan nol agar diperoleh nilai $\beta\left(u_{i}, v_{i}\right)$ dan $\alpha_{m}$ yang dapat memaksimumkan $L\left(\beta\left(u_{i}, v_{i}\right), \alpha_{m}\right)$. Selanjutnya karena hasil turunan pertama fungsi log likelihood terhadap masing-masing parameter tidak dapat diselesaikan secara analitik, maka digunakan metode iterasi Newton Raphson sebagai berikut:

$$
\begin{array}{r}
\left(\boldsymbol{\beta}^{(t+1)}\left(u_{i}, v_{i}\right), \boldsymbol{\alpha}^{(t+1)}\right)=\boldsymbol{\beta}^{(t)}\left(u_{i}, v_{i}\right), \boldsymbol{\alpha}^{(t)} \\
\left.-\left(\boldsymbol{H}^{(t)^{-1}}\left(\boldsymbol{\beta}^{(t)}\left(u_{i}, v_{i}\right), \boldsymbol{\alpha}^{(t)}\right)\right) \boldsymbol{g}^{(t)}\left(\boldsymbol{\beta}^{(t)}\left(u_{i}, v_{i}\right), \boldsymbol{\alpha}^{(t)}\right)\right),
\end{array}
$$

Iterasi berhenti pada saat konvergen, yaitu pada saat $\left\|\boldsymbol{\beta}^{(t+1)}\left(u_{i}, v_{i}\right), \boldsymbol{\alpha}^{(t+1)}\right\|=$ $\left\|\boldsymbol{\beta}^{(t)}\left(u_{i}, v_{i}\right), \boldsymbol{\alpha}^{(t)}\right\|$. Dengan menggunakan bantuan software R diperoleh hasil penaksir parameter. Tabel 3 menunjukkan statistik deskriptif $\left(\widehat{\boldsymbol{\beta}}\left(u_{i}, v_{i}\right), \widehat{\boldsymbol{\alpha}}\right)$ untuk semua lokasi.

Tabel 3. Penaksir parameter model semiparametrik GWLR

\begin{tabular}{ccc}
\hline Variabel & Minimum & Maksimum \\
\hline Intercept & -11.2545 & -8.8608 \\
\hline$x_{1}$ & -0.0128 & -0.0061 \\
\hline$x_{2}$ & -0.0754 & -0.0597 \\
\hline$x_{5}$ & -0.0138 & -0.0063 \\
\hline$x_{7}$ & -0.0577 & -0.0328 \\
\hline
\end{tabular}

Berdasarkan Tabel 3 dapat diketahui bahwa nilai penduga untuk parameter $x_{1}$ pada model semiparametrik GWLR memiliki nilai minimum sebesar -0.0128 dan nilai maksimum sebesar -0.0061. Nilai tersebut menunjukkan bahwa besar pengaruh rumah tangga dengan dinding tembok dan kayu berkisar antara -0.0128 sampai -0.0061. Penaksir parameter $x_{2}, x_{5}$ dan $x_{7}$ memiliki arti yang sama yaitu rumah dengan status kepemilikan sendiri dan rumah dengan status kepemilikan kontrak/sewa berkisar antara nilai minimum dan maksimum sesuai dengan Tabel 3.

Setiap kabupaten/kota memiliki model semiparametrik GWLR yang berbeda-beda. Hasil penaksir parameter untuk parameter global adalah bernilai sama untuk setiap lokasi yaitu $\alpha_{3}=0.1724, \alpha_{4}=0.0204$ dan $\alpha_{6}=0.0261$ sedangkan hasil penaksir parameter untuk parameter lokal memiliki nilai yang berbeda-beda, dapat dilihat pada Tabel 4. Selanjutnya model semiparametrik GWLR untuk tiap kabupaten/kota dapat dituliskan seperti berikut.

$$
\hat{\pi}\left(x_{1}\right)=\frac{\exp \left(-8.86-0.01 x_{1}-0.07 x_{2}+0.17 x_{3}+0.02 x_{4}-0.01 x_{5}+0.02 x_{6}-0.04 x_{7}\right)}{1+\exp \left(-8.86-0.01 x_{1}-0.07 x_{2}+0.17 x_{3}+0.02 x_{4}-0.01 x_{5}+0.02 x_{6}-0.04 x_{7}\right)}
$$


Pemodelan Semiparametrik Geographical Weigthed Logistic Regression...

Fitriatusakiah, Andi Kresna Jaya, La Podje Talangko

$$
\begin{gathered}
\hat{\pi}\left(x_{2}\right)=\frac{\exp \left(-10.41-0.01 x_{1}-0.06 x_{2}+0.17 x_{3}+0.02 x_{4}-0.006 x_{5}+0.02 x_{6}-0.043\right)}{1+\exp \left(-10.41-0.01 x_{1}-0.06 x_{2}+0.17 x_{3}+0.02 x_{4}-0.006 x_{5}+0.02 x_{6}-0.043\right)} \\
\vdots \\
\hat{\pi}\left(x_{24}\right)=\frac{\exp \left(-10.56-0.01 x_{1}-0.06 x_{2}+0.17 x_{3}+0.02 x_{4}-0.006 x_{5}+0.02 x_{6}-0.03 x_{7}\right)}{1+\exp \left(-10.56-0.01 x_{1}-0.06 x_{2}+0.17 x_{3}+0.02 x_{4}-0.006 x_{5}+0.02 x_{6}-0.03 x_{7}\right)}
\end{gathered}
$$

\begin{tabular}{|c|c|c|c|c|c|}
\hline Kabupaten & $\hat{\beta}_{0}$ & $\hat{\beta}_{1}$ & $\hat{\beta}_{2}$ & $\hat{\beta}_{5}$ & $\hat{\beta}_{7}$ \\
\hline Pangkep & -8.8607 & -0.0128 & -0.0754 & -0.0138 & -0.0412 \\
\hline Jenep & -10.4102 & -0.0112 & -0.0679 & -0.0064 & -0.0351 \\
\hline Toraj & -11.1093 & -0.0069 & -0.0609 & -0.0097 & -0.0540 \\
\hline Luwl & -11.1386 & -0.0061 & -0.0605 & -0.0105 & -0.0577 \\
\hline Luwu & -11.0807 & -0.0074 & -0.0612 & -0.0093 & -0.0519 \\
\hline Selayar & -10.1039 & -0.0120 & -0.0705 & -0.0063 & -0.0327 \\
\hline Enrekang & -11.0351 & -0.0081 & -0.0617 & -0.0087 & -0.0491 \\
\hline Tana toraja & -11.0746 & -0.0072 & -0.0612 & -0.0096 & -0.0526 \\
\hline Maros & -10.6535 & -0.0104 & -0.0656 & -0.0068 & -0.0384 \\
\hline Bone & -10.7651 & -0.0100 & -0.0645 & -0.0071 & -0.0403 \\
\hline Barru & -10.7879 & -0.0096 & -0.0642 & -0.0075 & -0.0417 \\
\hline Bantaeng & -10.4855 & -0.0112 & -0.0672 & -0.0063 & -0.0356 \\
\hline Takalar & -10.4099 & -0.0110 & -0.0678 & -0.0067 & -0.0356 \\
\hline Sinjai & -10.6368 & -0.0109 & -0.0658 & -0.0064 & -0.0374 \\
\hline Palopo & -11.1608 & -0.0073 & -0.0604 & -0.0093 & -0.0535 \\
\hline Pinrang & -10.9507 & -0.0082 & -0.0625 & -0.0087 & -0.0476 \\
\hline Soppeng & -10.8791 & -0.0094 & -0.0634 & -0.0075 & -0.0430 \\
\hline Gowa & -10.4947 & -0.0109 & -0.0671 & -0.0066 & -0.0362 \\
\hline Bulukumba & -10.4926 & -0.0112 & -0.0671 & -0.0063 & -0.0356 \\
\hline Luwu timur & -11.2546 & -0.0066 & -0.0596 & -0.0098 & -0.0570 \\
\hline Wajo & -10.9869 & -0.0089 & -0.0622 & -0.0080 & -0.0460 \\
\hline Parepare & -10.9478 & -0.0089 & -0.0626 & -0.0080 & -0.0453 \\
\hline Sidrap & -11.0003 & -0.0086 & -0.0621 & -0.0083 & -0.0470 \\
\hline Makassar & -10.5690 & -0.0106 & -0.0664 & -0.0068 & -0.0373 \\
\hline
\end{tabular}

Tabel 4. Nilai parameter lokal model semiparametrik GWLR

\section{Kesimpulan}

Kesimpulan dari hasil dan pembahasan adalah penaksir parameter model semiparametrik GWLR terdiri dari parameter yang bersifat lokal dan global sehingga setiap kabupaten/kota memiliki model Semiparametrik GWLR yang berbeda-beda. Model semiparametrik GWLR tiap kabupaten/kota di Sulawesi Selatan tahun 2017 dengan fungsi pembobot fixed Gaussian kernel yaitu: 
$\hat{\pi}\left(x_{i}\right)=\frac{\exp \left(\beta_{0}\left(u_{i}, v_{i}\right)+\beta_{1}\left(u_{i}, v_{i}\right) x_{1}+\beta_{2}\left(u_{i}, v_{i}\right) x_{2}+\alpha_{3} x_{3}+\alpha_{4} x_{4}+\beta_{5}\left(u_{i}, v_{i}\right) x_{5}+\alpha_{6} x_{6}+\beta_{7}\left(u_{i}, v_{i}\right) x_{7}\right)}{1+\exp \left(\beta_{0}\left(u_{i}, v_{i}\right)+\beta_{1}\left(u_{i}, v_{i}\right) x_{1}+\beta_{2}\left(u_{i}, v_{i}\right) x_{2}+\alpha_{3} x_{3}+\alpha_{4} x_{4}+\beta_{5}\left(u_{i}, v_{i}\right) x_{5}+\alpha_{6} x_{6}+\beta_{7}\left(u_{i}, v_{i}\right) x_{7}\right)}$

\section{Daftar Pustaka}

[1] Badan Pusat Statistik. Data dan Informasi Kemiskinan Sulawesi Selatan Tahun 2018. Makassar: BPS, 2018.

[2] Nakaya, T, Fotheringham A.S. \& Brudson C. Semiparametric geographically weighted Generalised Linier Model In GWR 4.0. Japan : Ritsumeikan University, 2005.

[3] Cressie, N.A.C. Statistics For Spatial Data. New York: John Wiley and Sons, Inc., 1993.

[4] Ribeiro, M.C., Sousa, A.J. \& Pereira, M.J. A Coregionalization Model Can Assist Spesification of Geographically Weighted Poisson Regression: Application to an Ecological study. Spatial and Spatio-temporal Epidemiology. 17(2016): 1-13, 2016.

[5] Isaaks, E.H. \& Srivastava, R.M. An Introduction to Applied Geostatistics. New York: Oxford University Press, 1989.

[6] Goulard, M. \& Voltz, M. Linier Coregionalization Model: Tools for Estimation and Choice of Cross-Variogram Matrix. Mathematical Geology. 24(3): 269-286, 1992.

[7] Anselin, L. Spatial Econometric : Methods and Models. Dordrecht: Kluwer Academic Publisher, 1998.

[8] Rosa, A.A. Penggunaan pembobot fixed kernel dan fixed bisquare kernel pada model Geographically Weighted Regression. Makassar, 2015.

[9] Chasco, C., Garcia, I., \& Vicens, J. Modeling spatial variations in household disposable income with Geographically Weighted Regression. Munich Personal RePEc Archive Paper No. 1682, 2007. 